\title{
Interleukin-8 and Acute Kidney Injury following Cardiopulmonary Bypass: A Prospective Cohort Study
}

\author{
Orfeas Liangos $^{\mathrm{a}} \quad$ Alexey Kolyada $^{\mathrm{a}}$ Hocine Tighiouart $^{\mathrm{b}}$ Mary C. Perianayagam $^{\mathrm{a}}$ \\ Ron Wald ${ }^{c}$ Bertrand L. Jaber ${ }^{a}$ \\ ${ }^{a}$ Division of Nephrology, Caritas St. Elizabeth's Medical Center, and biostatistics Research Center, \\ Tufts Medical Center, Boston, Mass., USA; 'Division of Nephrology, St. Michael's Hospital, Toronto, Ont., Canada
}

\section{Key Words}

Cardiac surgery $\cdot$ Acute kidney injury $\cdot$ Chemokine $\cdot$

Interleukin-8

\begin{abstract}
Background: Cardiopulmonary bypass (CPB) elicits an inflammatory response mediated partly by neutrophils, which are activated and recruited by interleukin-8 (IL-8). We hypothesized that acute kidney injury (AKI) following CPB might be mediated by IL- 8 and examined the association of perioperative plasma IL-8 levels with AKI in a prospective cohort. Methods: Plasma IL-8 was measured before, and 2, 24 and $48 \mathrm{~h}$ following CPB. Two AKI definitions, a serum creatinine increase of $\geq 0.3 \mathrm{mg} / \mathrm{dl}$ or $50 \%$ (AKI Network [AKIN] stage- 1 ) or $\geq 50 \%$ alone (AKI-50\%), within the first $72 \mathrm{~h}$, were used. Area under the receiver operator characteristic curves (AUCs) were generated and multivariable logistic regression analyses performed. Results: A total of 143 patients were enrolled. The baseline mean serum creatinine was $1.1 \mathrm{mg} /$ dl $(S D=0.3)$, the CPB perfusion time was $112 \mathrm{~min}(\mathrm{SD}=$ 43). Twenty-nine percent of the patients developed AKIN stage- 1 and $13 \%$ AKI-50\%. The plasma IL-8 level $2 \mathrm{~h}$ after CPB was higher in AKIN stage-1 ( $p=0.03)$ and AKI-50\% $(p<0.01)$,
\end{abstract}

and predicted AKIN stage-1 (AUC $=0.62 ; \mathrm{p}=0.02$ ) and AKI$50 \%$ ( $A \cup C=0.72 ; p<0.01$ ). On multivariable analysis, the $2-$ hour plasma IL-8 level was associated with 1.36- and 1.59fold higher odds for AKIN stage- 1 and AKI-50\%, respectively $(p=0.05)$. Conclusion: Plasma IL-8 predicts the development of AKI following CPB, supporting a potential involvement for this chemokine in the pathogenesis of AKI.

Copyright $\odot 2009$ S. Karger AG, Basel

\section{Introduction}

Acute kidney injury (AKI), as defined by a wide range of serum creatinine increments, develops in $5-20 \%$ of the patients undergoing cardiac surgery with cardiopulmonary bypass (CPB) $[1,2]$, with $1-2 \%$ requiring renal replacement therapy [3], and is associated with excessive in-hospital mortality $[1,4]$. The host inflammatory response elicited by CPB is driven in part by neutrophils, as a result of complement and contact activation by the extracorporeal circuit [5-8]. Activated neutrophils have been incriminated in the pathogenesis of AKI following CPB [9], and interleukin-8 (IL-8) is the primary endothelial-derived chemokine involved in the recruitment of

\section{KARGER}

๑ 2009 S. Karger AG, Basel

Fax +4161306 1234 E-Mail karger@karger.ch www.karger.com www.karger.com/nec
Orfeas Liangos, MD

Caritas St. Elizabeth's Medical Center

736 Cambridge Street, Boston, MA 02135 (USA)

Tel. +1 617562 7654, Fax +1 6177796064

E-Mail orfeas.liangos@caritaschristi.org 
neutrophils to injured organs such as the kidneys. IL- 8 is also a potent stimulant of several neutrophil cellular responses including chemotaxis, degranulation and respiratory burst $[10,11]$. The circulating IL- 8 levels increase following $\mathrm{CPB}[12,13]$, but the relationship of this chemokine to the development of post-CPB AKI has not been described.

It is important to note, however, that other mechanisms of neutrophil activation during CPB that are independent of IL- 8 have also been described, including adhesion molecules such as CD11b/CD18 [14] and E-selectin [15], as well as complement factors [16] that facilitate neutrophil-mediated organ injury. Other inflammatory mediators incriminated in direct organ injury following CPB include IL-6 [17], tumor necrosis factor- $\alpha$ [12, 18], platelet-activating factor, nitric oxide and arachidonic acid metabolites [19].

The objective of the present study was to test the hypothesis that the perioperative plasma IL- 8 profile is associated with the development of AKI in a large cohort of patients undergoing on-pump cardiac surgery, suggesting a functional role for this chemokine in the pathogenesis of acute organ injury.

\section{Patients and Methods}

\section{Study Design and Population}

This was a prospective cohort study of patients undergoing on-pump cardiac surgery performed between January 2004 and October 2007 at 2 tertiary-care hospitals located in Boston, Mass., USA. All consecutive patients $>18$ years of age undergoing onpump cardiac surgery (with or without valvular surgery, elective, urgent or emergent) were eligible for entry into the study. Pregnant women, patients with pre-existing AKI, end-stage renal disease on maintenance dialysis, solid organ or bone marrow transplant recipients, and those undergoing 'off-pump' or 'minimally invasive' coronary artery bypass grafting were excluded. Written informed consent was obtained from all participants prior to study enrollment. The institutional review board of each participating center approved the study protocol.

\section{Data Collection}

The medical records of the study participants were reviewed prospectively to retrieve preoperative variables including baseline demographic characteristics, coexisting conditions, intraoperative variables including $\mathrm{CPB}$ time, cross-clamp time as well as surgery type, and postoperative variables including serial serum creatinine values and the Acute Physiology and Chronic Health Evaluation (APACHE) II score [20], which was determined $24 \mathrm{~h}$ following $\mathrm{CPB}$ to serve as a measure of disease severity.
Serial Blood Sampling and Measurement of IL-8

At the time of enrolment, $8 \mathrm{ml}$ of EDTA-anticoagulated blood were collected. Subsequent $4-\mathrm{ml}$ blood samples were collected at 2,24 and $48 \mathrm{~h}$ after the discontinuation of CPB. The samples were kept on ice and processed within $30 \mathrm{~min}$ of collection. For plasma separation, the samples were centrifuged for $10 \mathrm{~min}$ at 3,000 rpm, followed by an additional $10 \mathrm{~min}$ at $13,000 \mathrm{rpm}$ after transfer of the supernatant. The plasma samples were then aliquoted and stored at $-80^{\circ} \mathrm{C}$ (REVCO Freezer; Thermo Fisher Scientific Inc., Waltham, Mass., USA).

IL-8 was measured in plasma using a solid-phase sandwich enzyme-linked immunosorbent assay, according to the manufacturer's instructions (R\&D Systems, Minneapolis, Minn., USA). The results are expressed in $\mathrm{pg} / \mathrm{ml}$. The assay's lower limit of detection is $3.5 \mathrm{pg} / \mathrm{ml}$. The intra- and interassay coefficient of variation is $3.9-6.6$ and $6.0-11.5 \%$, respectively.

\section{Outcome Measures}

The outcome measure was AKI defined as an increase in serum creatinine by $\geq 0.3 \mathrm{mg} / \mathrm{dl}$ or $\geq 50 \%$ in the first $72 \mathrm{~h}$ following $\mathrm{CPB}$. This serum creatinine criterion corresponds to stage- 1 of the AKI Network (AKIN) definition (AKIN stage-1) [21]. A second definition of AKI consisting of an increase in serum creatinine by $\geq 50 \%$ over the same time period (AKI-50\%) was also applied. This more stringent definition of AKI encompasses a subset of patients identified by AKIN stage-1. These 2 definitions were chosen to explore the robustness of our hypothesized associations across a spectrum of AKI. We chose the 72-hour time point instead of the 48-hour time point that is currently recommended by the AKIN definition [21], to account for the transient reduction in serum creatinine that may be observed following cardiac surgery due to hemodilution.

\section{Statistical Analyses}

Continuous variables were described as mean (SD) or median (interquartile range) and categorical variables as frequencies. Friedman's test was used to test for changes over time in perioperative plasma IL- 8 profile. The Wilcoxon rank sum test was used to compare plasma IL- 8 levels at the respective time points between patients with and without AKI. An area under the receiver operator characteristic curve analysis including calculation of 95\% confidence intervals (CI) for the area under the curve (AUC) was performed using the nonparametric method of DeLong et al. [22]. $\mathrm{p}$ values indicate significance compared to an AUC of 0.50 , which corresponds to chance.

Logistic regression analysis was also used to examine the association of plasma IL- 8 at the different time points and the development of AKI. Logistic regression models were generated to indicate odds ratios (OR) per doubling in plasma IL-8. Two multivariable models were developed to adjust for appropriate covariates: the first model adjusted for age and CPB perfusion time, whereas the second, expanded, model was overfitted with additional variables including preoperative serum creatinine, chronic obstructive pulmonary disease and peripheral vascular disease. For these analyses, plasma IL- 8 was log-transformed due to a skewed distribution. Differences were considered statistically significant at $p$ values $<0.05$. All statistical analyses were performed using SAS (SAS Institute, Cary, N.C., USA) version 9.1. For the figures, error bar graphs were generated, showing the 25th and 75 th percentile values around the median. 


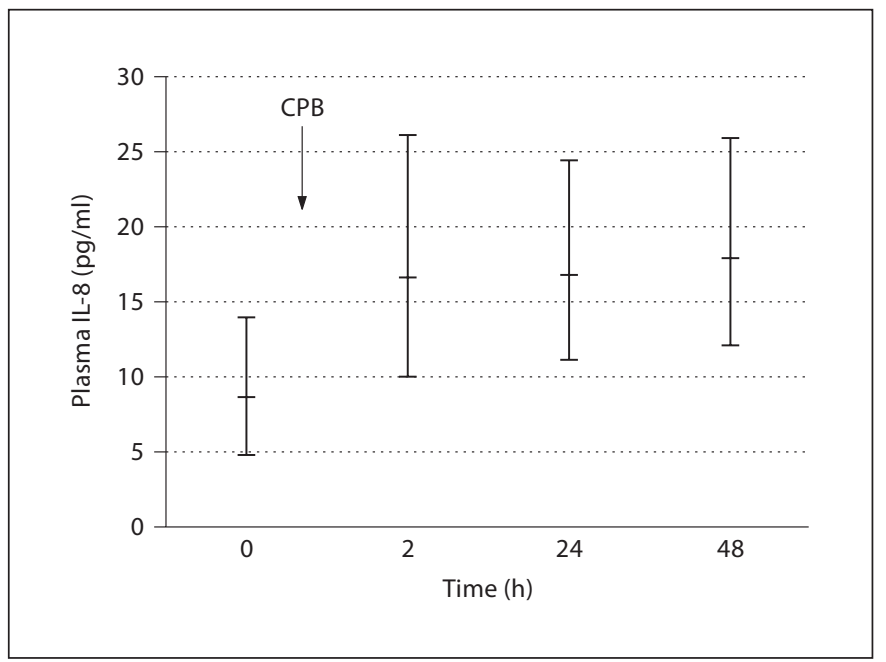

Fig. 1. Plasma IL-8 profile following CPB. Error bars represent 25th, 50th (median) and 75th percentile values. ${ }^{*} \mathrm{p}<0.0001$ by Friedman's test for overall difference between time points.

Table 1. Clinical characteristics of the study cohort $(\mathrm{n}=143)$

$\begin{array}{lc}\text { Preoperative variables } & \\ \text { Age, years } & 68(11) \\ \text { Women } & 32 \\ \text { White ethnicity } & 97 \\ \text { Hypertension } & 82 \\ \text { Diabetes mellitus } & 31 \\ \text { Baseline serum creatinine, mg/dl } & 1.1(0.3) \\ \text { Chronic lung disease } & 20 \\ \text { Congestive heart failure } & 27 \\ \text { Peripheral vascular disease } & 20 \\ \text { Cerebrovascular disease } & 8 \\ \text { Three-vessel coronary artery disease } & 52 \\ \text { Left main coronary artery disease } & 36 \\ \text { Left ventricular ejection fraction } & 51(14) \\ \text { Previous cardiac surgery } & 13 \\ \text { Operative variables } & \\ \text { Elective surgery } & 25 \\ \text { Valvular surgery } & 45 \\ \text { CPB perfusion time, min } & 112(43) \\ \text { Aortic cross-clamp time, min } & 85(34) \\ \text { Postoperative variables } & \\ \text { Total mechanical ventilation time, h } & 26(94) \\ \text { APACHE II score 24 after CPB } & 10(4)\end{array}$

Data are shown as means (SD) or percent.

\section{Results}

\section{Characteristics of the Cohort}

A total of 143 subjects were enrolled. Table 1 displays the characteristics of the cohort, reflecting a patient population with established risk factors for cardiovascular disease but with relatively well-preserved left ventricular function and preoperative kidney function. In brief, their mean age was 68 years, 97\% were Caucasian, and 32\% were women, with a mean preoperative left ventricular ejection fraction of $51 \%$. Approximately $25 \%$ of the patients underwent elective cardiac surgery with a mean CPB perfusion and aortic cross-clamp time of 112 and 85 min, respectively. The preoperative administration of radiocontrast, which occurred in $62 \%$ of the patients, was neither associated with preoperative serum creatinine levels nor with the development of postoperative AKI (data not shown). Twenty-four hours after CPB, the mean APACHE II score was 10. AKIN stage-1 developed in 41 (29\%) and (AKI-50\%) in 18 subjects (13\%).

\section{Association of the Plasma IL-8 Profile with \\ Postoperative AKI}

As shown in figure $1, \mathrm{CPB}$ resulted in a predictable increase in plasma IL-8 levels perioperatively ( $<<0.0001)$. Subjects who developed AKIN stage-1 had a significantly higher plasma IL-8 level 2 and $48 \mathrm{~h}$ after CPB, as compared to those who did not develop AKIN stage-1 ( $p=$ 0.03 and $p<0.01$, respectively; fig. 2a). However, the difference at the 24-hour time point did not reach statistical significance $(\mathrm{p}=0.09)$. Similarly, subjects who developed AKI-50\% had a significantly and consistently higher plasma IL-8 level 2, 24 and $48 \mathrm{~h}$ after $\mathrm{CPB}$, as compared to those who did not develop AKI-50\% ( $\mathrm{p}<0.01, \mathrm{p}=0.02$ and $\mathrm{p}<0.01$, respectively; fig. $2 \mathrm{~b}$ ).

On univariate analysis (table 2), the plasma IL-8 level 2 and $48 \mathrm{~h}$ after CPB was associated with 1.44 -fold (95\% $\mathrm{CI}=1.07-1.95 ; \mathrm{p}=0.02)$ and 1.73 -fold $(95 \% \mathrm{CI}=1.08$ 2.77; $\mathrm{p}=0.02$ ) higher odds for AKIN stage-1, respectively. All post-CPB plasma IL-8 levels, at $2 \mathrm{~h}(\mathrm{OR}=1.60 ; 95 \%$ $\mathrm{CI}=1.06-2.40 ; \mathrm{p}=0.03), 24 \mathrm{~h}(\mathrm{OR}=2.02 ; 95 \% \mathrm{CI}=1.16-$ $3.51 ; \mathrm{p}=0.01)$ and $48 \mathrm{~h}(\mathrm{OR}=1.87 ; 95 \% \mathrm{CI}=1.07-3.29$; $\mathrm{p}=0.03)$ were significantly associated with AKI-50\%. Other factors related to AKIN stage- 1 were age $(\mathrm{OR}=$ $1.48 ; 95 \% \mathrm{CI}=1.04-2.12 ; \mathrm{p}=0.03)$ per 10 -year increment and $\mathrm{CPB}$ time, per 1-hour increment, for both AKIN stage-1 $(\mathrm{OR}=1.78 ; 95 \% \mathrm{CI}=1.06-2.97 ; \mathrm{p}=0.03)$ and AKI-50\% (OR $=3.52 ; 95 \% \mathrm{CI}=1.71-7.25 ; \mathrm{p}<0.01)$. On multivariable analysis, the association of the plasma IL-8 level $2 \mathrm{~h}$ after CPB persisted with 1.36-fold (95\% 

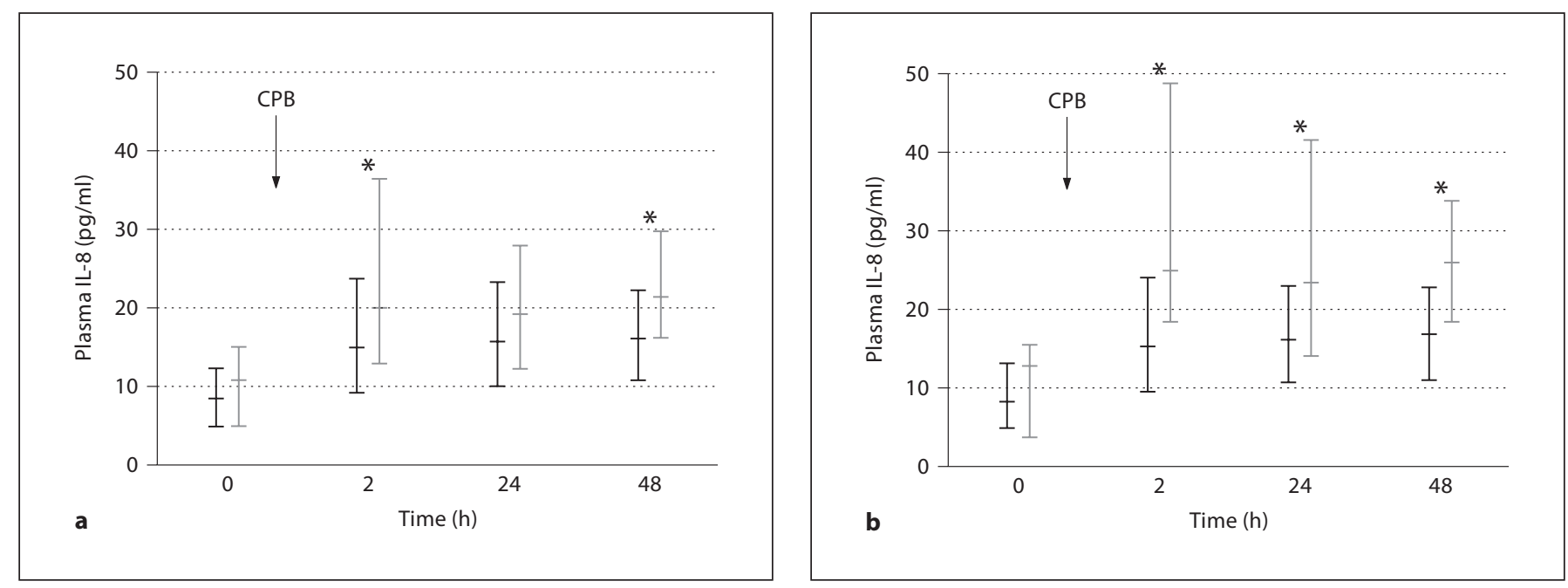

Fig. 2. Median plasma IL-8 profile following CPB stratified by AKIN stage-1 (a) and AKI-50\% (b). The AKI group is displayed in gray and the non-AKI group in black. Error bars represent 25 th and 75 th percentile values. ${ }^{*} \mathrm{p}<0.05$ vs. non-AKI by Wilcoxon rank sum test.

$\mathrm{CI}=1.00-1.86 ; \mathrm{p}=0.05)$ and 1.59 -fold higher odds $(95 \%$ $\mathrm{CI}=1.01-2.52 ; \mathrm{p}=0.05)$, respectively, for AKIN stage-1 and $\mathrm{AKI}-50 \%$, after adjustment for age and CPB perfusion time (table 2). The association of the plasma IL- 8 levels $48 \mathrm{~h}$ after CPB with AKIN stage- 1 and AKI-50\% was also maintained after adjustment for age and CPB perfusion time (table 2). The relationship between plasma IL-8 levels and AKI was maintained after adjustment for additional covariates (table 2).

\section{Performance Characteristics of the Perioperative}

Plasma IL-8 Profile for Predicting AKI

Table 3 displays the performance characteristics of plasma IL- 8 at the various time points for the prediction of AKI, compared to age and CPB perfusion time, 2 known risk factors for the development of AKI. At the 2-, 24- and 48-hour post-CPB time point, the AUC for plasma IL-8 was $0.62(\mathrm{p}=0.02), 0.59(\mathrm{p}=0.08)$ and $0.68(\mathrm{p}=$ $0.01)$ for the prediction of AKIN stage- 1 , and $0.72(\mathrm{p}<$ $0.01), 0.67(\mathrm{p}=0.03)$ and $0.73(\mathrm{p}<0.01)$ for AKI-50\%, respectively. Similar results were obtained in a sensitivity analysis restricted to the 36 study participants who underwent elective cardiac surgery (data not shown). Plasma IL-8 predicted both AKIN stage- 1 and AKI-50\% fairly well, and its performance was marginally but not significantly higher than that of CPB perfusion time for the prediction of AKIN stage-1, as illustrated by the substantial overlap of the $95 \%$ CI (table 3 ).

Plasma IL-8 and AKI following Cardiac Surgery

\section{Discussion}

AKI following on-pump cardiac surgery is a serious complication that is associated with significantly increased morbidity and mortality $[1,4]$. Despite its significance, the mechanisms of kidney injury in this clinical setting are still not fully understood. Our study describes the kinetics of plasma IL-8 in response to CPB and the strength of its association with the development of postoperative AKI. The results indicate that the IL-8 plasma levels increase consistently in response to $\mathrm{CPB}$, but the rise is more pronounced among patients who develop AKI compared to those who do not. This increased plasma IL-8 response among patients who developed AKI could be registered as early as $2 \mathrm{~h}$ following CPB and displayed moderate discrimination for the early detection of AKI. The diagnostic performance of plasma IL-8 for the early detection of AKI was less robust compared to urinary biomarkers such as neutrophil gelatinase-associated lipocalin [23]. On multivariable analysis, however, plasma IL-8 remained independently associated with the development of AKI, after adjustment for important clinical risk factors for AKI, suggesting a potential involvement of this chemokine in this disorder.

A large body of literature exists on the role and function of IL-8 in neutrophil-mediated inflammatory responses (reviewed in detail in Hoch et al. [24]). In addition to its primary role as a neutrophil chemotactic agent, IL-8 stimulates the neutrophil oxidative burst [25]. Plas-

Nephron Clin Pract 2009;113:c148-c154 
Table 2. Association of plasma IL-8 levels with the development of post-CPB AKI

\begin{tabular}{|c|c|c|c|c|c|c|}
\hline \multirow[t]{2}{*}{ Predictor variable } & \multicolumn{3}{|c|}{ AKIN stage I } & \multicolumn{3}{|c|}{ AKI- $50 \%$} \\
\hline & OR & $95 \% \mathrm{CI}$ & $\mathrm{p}$ value & OR & $95 \% \mathrm{CI}$ & $\mathrm{p}$ value \\
\hline \multicolumn{7}{|l|}{ Unadjusted } \\
\hline Before CBP & 1.27 & $0.88-1.83$ & 0.20 & 1.41 & $0.87-2.29$ & 0.16 \\
\hline Two hours after CBP & 1.44 & $1.07-1.95$ & 0.02 & 1.60 & $1.06-2.40$ & 0.03 \\
\hline Twenty-four hours after CBP & 1.40 & $0.94-2.09$ & 0.10 & 2.02 & $1.16-3.51$ & 0.01 \\
\hline Forty-eight hours after CBP & 1.73 & $1.08-2.77$ & 0.02 & 1.87 & $1.07-3.29$ & 0.03 \\
\hline \multicolumn{7}{|c|}{ Adjusted for age and CPB perfusion time } \\
\hline Before $\mathrm{CBP}^{1}$ & 1.21 & $0.83-1.75$ & 0.33 & 1.34 & $0.82-2.19$ & 0.24 \\
\hline Two hours after CBP & 1.36 & $1.00-1.86$ & 0.05 & 1.59 & $1.01-2.52$ & 0.05 \\
\hline Twenty-four hours after CBP & 1.31 & $0.84-2.03$ & 0.23 & 1.67 & $0.87-3.19$ & 0.12 \\
\hline Forty-eight hours after CBP & 1.71 & $1.03-2.82$ & 0.04 & 2.24 & $1.14-4.41$ & 0.02 \\
\hline \multicolumn{7}{|c|}{$\begin{array}{l}\text { Adjusted for age, chronic lung disease, peripheral vascular disease, preoperative serum creatinine and } \\
\text { CPB perfusion time }\end{array}$} \\
\hline Before $\mathrm{CBP}^{1}$ & 1.29 & $0.87-1.90$ & 0.21 & 1.53 & $0.92-2.56$ & 0.10 \\
\hline Two hours after CBP & 1.40 & $1.00-1.97$ & 0.05 & 1.98 & $1.18-3.32$ & $<0.01$ \\
\hline Twenty-four hours after CBP & 1.14 & $0.73-1.77$ & 0.58 & 1.45 & $0.81-2.60$ & 0.22 \\
\hline Forty-eight hours after CBP & 1.72 & $1.04-2.85$ & 0.04 & 2.34 & $1.17-4.67$ & 0.02 \\
\hline
\end{tabular}

AKIN stage- 1 is defined as serum creatinine increase by $\geq 0.3 \mathrm{mg} / \mathrm{dl}$ or $50 \%$ in the first $72 \mathrm{~h}$ following CPB; AKI-50\% is defined as serum creatinine increase by $\geq 50 \%$ in the first $72 \mathrm{~h}$ following CPB. Logistic regression models were generated to indicate odds ratios per doubling in plasma IL-8.

${ }^{1} \mathrm{CPB}$ time not included as measurement precedes $\mathrm{CPB}$.

ma IL-8 has previously been shown to increase following on-pump cardiac surgery $[26,27]$, and post-CPB peak plasma IL-8 levels have been associated with prolonged mechanical ventilation [27] and worse arterial oxygenation parameters [28].

Published clinical reports on the relationship of IL-8 with AKI are limited. One study demonstrated an association of urinary IL-8 levels with sustained renal allograft dysfunction due to ischemia-reperfusion injury [29]. Serial plasma IL-8 levels have previously been shown to predict the development of AKI in patients with sepsis [30]. Among critically ill patients with AKI, plasma IL-8 levels have also been shown to be higher among nonsurvivors of hospitalization [31].

In keeping with this previous work, our study confirms that IL-8 does respond to on-pump cardiac surgery with a moderate but significant increase in plasma levels. In addition and more importantly, patients who develop AKI following CPB display a significantly more pronounced elevation of plasma IL-8 early on. This observation was consistent across 2 distinct creatinine-based definitions of AKI, thereby supporting the robustness of the results. Furthermore, the plasma IL- 8 level, $2 \mathrm{~h}$ after $\mathrm{CPB}$, predicted the development of AKIN stage-1, al- though its performance was similar to $\mathrm{CPB}$ perfusion time, a known predictor of AKI (see table 3). Of note, the plasma IL- 8 levels 2 and $48 \mathrm{~h}$ after CPB remained independently associated with both AKIN stage- 1 and AKI$50 \%$ after adjusting for age, CPB perfusion time, chronic lung disease, peripheral vascular disease and preoperative serum creatinine, attenuating the potential confounding effect of these important covariates and known risk factors for the development of AKI following cardiac surgery.

Our study has some strengths and limitations that are worthy of mention. To our knowledge, this is the first prospective cohort study testing the hypothesis that plasma IL-8, the primary chemotactic agent involved in tissue neutrophil recruitment following ischemia-reperfusion injury, is associated with the development of AKI in a large relatively unselected cohort of patients undergoing on-pump cardiac surgery. We observed a fairly consistent association between plasma IL-8 measured at different, postoperative time points and the development of $\mathrm{AKI}$, as well as across the spectrum of 2 AKI definitions, which are both included in the AKIN definition [21]. The associations are mild and the prediction of AKI using receiver operator characteristic curves is at best moderate. 
Table 3. AUC of selected variables for the prediction of AKI

\begin{tabular}{|c|c|c|c|c|c|c|}
\hline \multirow[t]{2}{*}{ Predictor variable } & \multicolumn{3}{|c|}{ AKIN stage-1 } & \multicolumn{3}{|c|}{ AKI-50\% } \\
\hline & AUC & $95 \% \mathrm{CI}$ & $\mathrm{p}$ value & AUC & $95 \% \mathrm{CI}$ & $\mathrm{p}$ value \\
\hline \multicolumn{7}{|l|}{ Plasma IL-8 } \\
\hline Before CPB & 0.58 & $0.47-0.69$ & 0.16 & 0.59 & $0.42-0.75$ & 0.31 \\
\hline Two hours after CPB & 0.62 & $0.52-0.73$ & 0.02 & 0.72 & $0.61-0.84$ & $<0.01$ \\
\hline Twenty-four hours after CPB & 0.59 & $0.49-0.70$ & 0.08 & 0.67 & $0.52-0.82$ & 0.03 \\
\hline Forty-eight hours after $\mathrm{CPB}$ & 0.68 & $0.57-0.79$ & 0.01 & 0.73 & $0.60-0.85$ & $<0.01$ \\
\hline Age & 0.60 & $0.51-0.70$ & 0.03 & 0.61 & $0.48-0.75$ & 0.09 \\
\hline CPB perfusion time & 0.59 & $0.49-0.70$ & 0.07 & 0.73 & $0.60-0.85$ & $<0.01$ \\
\hline
\end{tabular}

AKIN stage- 1 is defined as a serum creatinine increase by $\geq 0.3 \mathrm{mg} / \mathrm{dl}$ or $50 \%$ in the first $72 \mathrm{~h}$ following CPB; $\mathrm{AKI}-50 \%$ is defined as a serum creatinine increase by $\geq 50 \%$ in the first $72 \mathrm{~h}$ following $\mathrm{CPB}$. $\mathrm{p}$ value compares to AUC of 0.50 , representing chance.

In addition, the observed association of IL-8 with AKI cannot serve as proof of a functional role in the pathogenesis of this complex disorder. Our results are nevertheless important, since they demonstrate for the first time an association of plasma IL-8 with AKI in cardiac surgery. It should be noted that a previous study has shown that circulating IL-8 is primarily bound to erythrocytes, which act as a sink and might have influenced our results by reducing the extent of the plasma IL- 8 rise by erythrocyte binding [32]. In addition, the administration of heparin might attenuate the proinflammatory effects of IL-8 through binding [33]. Since all study participants in our cohort received heparin during $\mathrm{CPB}$, both the AKI and non-AKI groups were equally exposed to heparin, which, in turn, should not bias our results.

In summary, the results of our study demonstrate that among adults undergoing on-pump cardiac surgery, the perioperative plasma IL-8 levels predict the development of AKI, pointing toward a potential involvement of this chemokine in AKI. Larger studies are needed to confirm these relationships.

\section{Acknowledgments}

This study was presented in part at the 40th Annual Meeting of the American Society of Nephrology, San Francisco, Calif., USA, October 31 to November 5, 2007. This study was supported by a grant from the American Heart Association (No. 0535367N to O.L.). B.L.J. is supported by grants from the National Institutes of Health (DK065102 and R03DK077751). The authors thank Robert W. MacKinnon RN, CNN, for his assistance with patient enrollment and data collection.

\section{References}

Plasma IL-8 and AKI following Cardiac Surgery
1 Lassnigg A, Schmidlin D, Mouhieddine M, Bachmann LM, Druml W, Bauer P, Hiesmayr M: Minimal changes of serum creatinine predict prognosis in patients after cardiothoracic surgery: a prospective cohort study. J Am Soc Nephrol 2004;15:15971605.

2 Liangos $\mathrm{O}$, Han WK, Wald R, Perianayagam MC, Balakrishnan VS, MacKinnon RW, Warner K, Symes JF, Li L, Kouznetsov A, Pereira BJG, Bonventre JV, Jaber BL: Urinary kidney injury molecule-1 (KIM-1) and $\mathrm{N}$ $\operatorname{acetyl}(\beta)$-D-glucosaminidase (NAG) levels in patients undergoing cardiac surgery with cardiopulmonary bypass (CPB). J Am Soc Nephrol 2005;16:318A.
3 Bahar I, Akgul A, Ozatik MA, Vural KM, Demirbag AE, Boran M, Tasdemir O: Acute renal failure following open heart surgery: risk factors and prognosis. Perfusion 2005; 20:317-322.

-4 Chertow GM, Levy EM, Hammermeister KE, Grover F, Daley J: Independent association between acute renal failure and mortality following cardiac surgery. Am J Med 1998; 104:343-348.

5 Kuijpers TW, Hakkert BC, Hart MH, Roos D: Neutrophil migration across monolayers of cytokine-prestimulated endothelial cells: a role for platelet-activating factor and IL-8. J Cell Biol 1992;117:565-572.
(⿸丆口 
$\checkmark 6$ Elgebaly SA, Houser SL, el Kerm AF, Doyle K, Gillies C, Dalecki K: Evidence of cardiac inflammation after open heart operations. Ann Thorac Surg 1994;57:391-396.

-7 Cremer J, Martin M, Redl H, Bahrami S, Abraham C, Graeter T, Haverich A, Schlag G, Borst HG: Systemic inflammatory response syndrome after cardiac operations. Ann Thorac Surg 1996;61:1714-1720.

$\checkmark 8$ Wan S, LeClerc JL, Vincent JL: Inflammatory response to cardiopulmonary bypass: mechanisms involved and possible therapeutic strategies. Chest 1997;112:676-692.

$\checkmark 9$ Rinder CS, Fontes M, Mathew JP, Rinder HM, Smith BR: Neutrophil CD11b upregulation during cardiopulmonary bypass is associated with postoperative renal injury. Ann Thorac Surg 2003;75:899-905.

-10 Peveri P, Walz A, Dewald B, Baggiolini M: A novel neutrophil-activating factor produced by human mononuclear phagocytes. J Exp Med 1988;167:1547-1559.

-11 Thelen M, Peveri P, Kernen P, von Tscharner V, Walz A, Baggiolini M: Mechanism of neutrophil activation by NAF, a novel monocyte-derived peptide agonist. Faseb J 1988;2: 2702-2706.

-12 McBride WT, Armstrong MA, Crockard AD, McMurray TJ, Rea JM: Cytokine balance and immunosuppressive changes at cardiac surgery: contrasting response between patients and isolated CPB circuits. $\mathrm{Br}$ J Anaesth 1995;75:724-733.

-13 Kawamura T, Wakusawa R, Okada K, Inada $\mathrm{S}$ : Elevation of cytokines during open heart surgery with cardiopulmonary bypass: participation of interleukin 8 and 6 in reperfusion injury. Can J Anaesth 1993;40:10161021.

-14 Horgan MJ, Wright SD, Malik AB: Antibody against leukocyte integrin (CD18) prevents reperfusion-induced lung vascular injury. Am J Physiol 1990;259:L315-L319.

- 15 Lehle K, Preuner JG, Vogt A, Rupprecht L, Keyser A, Kobuch R, Schmid C, Birnbaum DE: Endothelial cell dysfunction after coronary artery bypass grafting with extracorporeal circulation in patients with type 2 diabetes mellitus. Eur J Cardiothorac Surg 2007; 32:611-616.
16 Elliott MJ, Finn AH: Interaction between neutrophils and endothelium. Ann Thorac Surg 1993;56:1503-1508.

-17 Podgoreanu MV, Michelotti GA, Sato Y, Smith MP, Lin S, Morris RW, Grocott HP Mathew JP, Schwinn DA: Differential cardiac gene expression during cardiopulmonary bypass: ischemia-independent upregulation of proinflammatory genes. J Thorac Cardiovasc Surg 2005;130:330-339.

18 Duggan E, Caraher E, Gately K, O’Dwyer M, McGovern E, Kelleher D, McManus R, Ryan T: Tumor necrosis factor- $\alpha$ and interleukin-10 gene expression in peripheral blood mononuclear cells after cardiac surgery. Crit Care Med 2006;34:2134-2139.

19 Jorres A, Kordonouri O, Schiessler A, Hess S, Farke S, Gahl GM, Muller C, Djurup R: Urinary excretion of thromboxane and markers for renal injury in patients undergoing cardiopulmonary bypass. Artif Organs 1994;18: 565-569.

20 Knaus WA, Draper EA, Wagner DP, Zimmerman JE: APACHE II: a severity of disease classification system. Crit Care Med 1985; 13 : 818-829.

21 Mehta RL, Kellum JA, Shah SV, Molitoris BA, Ronco C, Warnock DG, Levin A: Acute Kidney Injury Network: report of an initiative to improve outcomes in acute kidney injury. Crit Care 2007;11:R31.

22 DeLong ER, DeLong DM, Clarke-Pearson DL: Comparing the areas under two or more correlated receiver operating characteristic curves: a nonparametric approach. Biometrics 1988;44:837-845.

23 Parikh CR, Mishra J, Thiessen-Philbrook H Dursun B, Ma Q, Kelly C, Dent C, Devarajan $\mathrm{P}$, Edelstein CL: Urinary IL-18 is an early predictive biomarker of acute kidney injury after cardiac surgery. Kidney Int 2006;70:199203.

24 Hoch RC, Schraufstatter IU, Cochrane CG In vivo, in vitro, and molecular aspects of interleukin- 8 and the interleukin- 8 receptors. J Lab Clin Med 1996;128:134-145.

25 Elbim C, Bailly S, Chollet-Martin S, Hakim J, Gougerot-Pocidalo MA: Differential priming effects of proinflammatory cytokines on human neutrophil oxidative burst in response to bacterial $\mathrm{N}$-formyl peptides. Infect Immun 1994;62:2195-2201.
26 Alatas O, Colak O, Buyukkidan B, Portakal O, Tanriverdi B: Soluble interleukin-2 receptor and interleukin-8 plasma levels during and after cardiopulmonary bypass: correlations with creatine kinase and creatine kinase MB. Clin Exp Med 2001;1:13-18.

27 Rothenburger M, Tjan TD, Schneider M, Berendes E, Schmid C, Wilhelm MJ, Bocker D, Scheld HH, Soeparwata R: The impact of the pro- and anti-inflammatory immune response on ventilation time after cardiac surgery. Cytometry 2003;53B:70-74.

28 Gessler P, Pfenninger J, Pfammatter JP, Carrel T, Baenziger $\mathrm{O}$, Dahinden C: Plasma levels of interleukin- 8 and expression of interleukin-8 receptors on circulating neutrophils and monocytes after cardiopulmonary bypass in children. J Thorac Cardiovasc Surg 2003;126:718-725.

-29 Kwon O, Molitoris BA, Pescovitz M, Kelly KJ: Urinary actin, interleukin-6, and interleukin-8 may predict sustained ARF after ischemic injury in renal allografts. Am J Kidney Dis 2003;41:1074-1087.

30 Ahlstrom A, Hynninen M, Tallgren M, Kuusela P, Valtonen M, Orko R, Siitonen S, Takkunen O, Pettila V: Predictive value of interleukins 6, 8 and 10, and low HLA-DR expression in acute renal failure. Clin Nephrol 2004;61:103-110.

-31 Simmons EM, Himmelfarb J, Sezer MT, Chertow GM, Mehta RL, Paganini EP, Soroko S, Freedman S, Becker K, Spratt D, Shyr Y, Ikizler TA: Plasma cytokine levels predict mortality in patients with acute renal failure. Kidney Int 2004;65:1357-1365.

32 Tilg H, Pape D, Trehu E, Shapiro L, Atkins MB, Dinarello CA, Mier JW: A method for the detection of erythrocyte-bound interleukin-8 in humans during interleukin-1 immunotherapy. J Immunol Methods 1993;163: 253-258.

33 Ramdin L, Perks B, Sheron N, Shute JK: Regulation of interleukin- 8 binding and function by heparin and $\alpha 2$-macroglobulin. Clin Exp Allergy 1998;28:616-624. 